\title{
ROTINAS E NORMAS TÉCNICAS DE UM BANCO DE LEITE HUMANO E CENTRAL DE INFORMAÇŌES SOBRE ALEITAMENTO MATERNO.
}

\author{
Evanguelia Kotzias Atherino dos Santos ${ }^{1}$ e \\ Maria Alice Altenburg de Assis $^{2}$
}

SANTOS, E. K. A. \& ASSIS, M. A. A. Rotinas e normas técnicas de um banco de leite humano e central de informaçōes sobre aleitamento materno. Rev. Bras. Enf., Brasília. 38(2): 133-137, abr.jjun. 1985.

\begin{abstract}
RESUMO. A elaboração e publicação de normas técnicas e rotinas é um investimento positivo para toda instituição que trabalha à base de objetivos e deseja avaliar seus resultados. As autoras, preocupadas em colaborar com as instituições que pretendem implantar este serviço, apresentam neste trabalho as normas técnicas e rotinas relacionadas com a recepção e triagem das nutrizes, coleta interna e domiciliar, preparo e esterilização de material, processamento e distribuição do leite coletado. Elas são adotadas pelo Banco de Leite Humano e Central de Informações sobre Aleitamento Materno da Maternidade Carmela Dutra e foram elaboradas com base na experiência de dois anos de trabalho.
\end{abstract}

ABSTRACT. The preparation and publication of the technical rules and procedures is a positive investment for all institution that works based on objectives and desires to analyse their results. The authors concerned in contributing to the institutions which intend to implant this service, present in this work the technical rules and procedures connected to the reception and selection of wet - nurses, internal and home collection of the milk preparation and sterilization of the material, the storage and analysis of the milk in laboratories and the destiny of this collected milk. Those technical rules and procedures are adopted by the HUMAN MILK BANK AND INFORMATION CENTER ON MATERNAL MILK, FEEDING OF THE CARMELA DUTRA MATERNITY WARD. They had heen worked out based on two years experiment.

\section{INTRODUÇÃO}

Assiste-se, há alguns anos. um despertar renovado pela prática de amamentação ao seio. em virtude dos benefícios que advêm para a saúde do binômio mãe e filho.

O leite humano e, em especial, o colostro parecem ser mais importantes para a proteção e sobrevivència de certo grupo de recém-nascidos. Incluem-se neste os prematuros. os de baixo pe- so ao nascer, os propensos a infecçōes graves, os recém-nascidos com enterocolite necrotizante, os alérgicos ao leite de vaca e os imunodeficientes $\left(\right.$ ASSIS $\left.^{2}\right)$.

Nas Unidades de Internação dos recém-nascidos de baixo peso, freqüentemente se observam epidemias de diarréia aguda, produzidas por Escherichia coli enteropatogènica.

A utilizaçāo do leite humano revelou-se como único meio efícaz de dominar as epidemias infec-

\footnotetext{
1 Professor Assistente do Departamento de Enfermagem da Universidade Federal de Santa Catarina e Chefe do Servi-

ço de Enfermagem da Maternidade Carmela Dutra. F. H. S. C.. Florianópolis. SC - Brasil.

2 Coordenadora de Alimentação e Nutrição da Fundação Hospitalar de Santa Catarina, Florianópolis, SC - Brasil.
} 
ciosas nestas unidades (BULLEN \& ROGERS ${ }^{6}$ ), além de desempenhar papel relevante no estabelecimento da colonização intestinal do recém-nascido prematuro (FERNANDEZ ${ }^{9}$ ).

O colostro apresenta, ainda, uma composição bioquímica e imunológica própria para a recuperação destas crianças (McCLELLAND ${ }^{15}$, NORDIO et alii ${ }^{16}$, PITT \& PORTER ${ }^{17}$ ).

Após o lançamento do Programa Nacional de Aleitamento Materno, houve um crescente interesse pela implantaçāo de Bancos de Leite Humano os quais. através de coleta, processamento e estocagem apropriados, poderiam suprir as necessidades dos bebès internados em Unidades de Tratamento Intensivo das maternidades e hospitais infantis.

Com o intuito de colaborar com as instituições que pretendem implantar este serviço, apresentamos neste trabalho as normas técnicas e rotinas adotadas pelo Banco de Leite Humano e Central de Informaçōes sobre Aleitamento Materno da Maternidade Carmela Dutra, elaboradas com base na experiência acumulada em dois anos de trabalho.

\section{LOCALIZAÇÃO, ESTRUTURA FÍSICA E RECURSOS HUMANOS}

A Maternidade Carmela Dutra faz parte da estrutura organizacional da Fundação Hospitalar de Santa Catarina, com sede em Florianópolis e recebe pacientes de todas as categorias sociais, pois se trata de uma Maternidade Escola, conveniada com a Universidade Federal de Santa Catarina (UFSC), INAMPS e outras Instituiçōes. Possui um total de 95 leitos, dos quais 78 são destinados à clientela não contribuinte e previdenciária e 17 leitos para particulares. A Fundaçāo Hospitalar é composta de outras unidades hospitalares e assistenciais. localizadas na Capital e no interior do Estado. O Banco de Leite Humano e Central de Informaçōes sobre Aleitamento Materno foi instalado em local de fácil acesso ao público. Postos de Coleta com estrutura física mais simples foram montados em outras maternidades é hospitais da Fundação Hospitalar.

A írea física do Banco de Leite da Maternidade Carmela Dutra está constituída de cinco salas, quais sejam: recepção e triagem das doadoras. coleta de leite. preparo e esterilização de material, estocagem e laboratório. A equipe técnica profissional é composta por enfermeiros, nutricionistas, tecnólogo de alimentos. pediatras, obstetras e assistentes sociais, todos funcionários da própria instituição. Além da equipe técnica, contamos com o trabalho de duas atendentes de enfermagem e de estagiários de cursos universitários da área da saúde $\left(\operatorname{ASSIS}^{3}\right)$.

\section{NORMAS TÉCNICAS E ROTINAS}

\section{Da Recepção e Triagem}

- Toda cliente atendida no Banco de Leite recebe orientaçōes e informaçōes técnico-científicas sobre a prática da amamentação, quer individualmente, em grupo, ou por telefone.

- Os dados médico-sociais das doadoras são anotados em livro próprio, sendo registrados a data de coleta, nome, endereço, número de filhos, idade, quantidade coletada, idade do leite (a partir da hora do parto), uso de drogas ou medicamentos.

- As puérperas nutrizes com alta hospitalar sāo cadastradas diariamente em formulário próprio, sendo os endereços notificados com precisão para posterior coleta a domicilio (Anexo I).

- Em outro formulário também é registrado todo o destino do leite coletado, seja de doadoras extermas ou internas (Anexo II).

- As mães de recém-nascidos prematuros e de baixo peso recebem orientaçōes especiais. estimulando-as a comparecerem diariamente ao Banco de Leite, a fim de que seus filhos sejam beneficiados com o leite materno.

- As doadoras carentes são inscritas no Programa de Nutrição em Saúde (PNS), da Secretaria Estadual de Saúde e poderão receber passes de ónibus quando, após a alta hospitalar. seus filhos ainda permanecerem internados.

- Todas as doadoras recebem propés e gorro antes de serem encaminhadas para a sala de coleta.

- O Banco de Leite presta serviços diariamente das 7:00 às 22:00 horas. exceto sábados. domingos e feriados com atendimento das 7:00 às 18:00 horas.

- As doadoras recebem folhetos contendo orientações sobre aleitamento materno e coleta domiciliar (Anexo III). 


\section{DA COLETA}

As doadoras deverão:

- Proceder a lavagem das mãos obedecendo aos princípios de assepsia médica.

- Retirar vestuário em uso, lavar as mamas com água aquecida, fazendo massagens.

- Enxugar apenas as mãos.

- Colocar avental próprio utilizado pelo Banco de Leite (com fenda vertical no local das mamas).

- Colocar máscara.

- Ficar em posição confortável para proceder-se a retira da do leite.

- Ser orientadas para colaborar na extração do leite, fazendo massagens intermitentes.

Os funcionários deverão:

- Demonstrar habilidade e delicadeza no trato com as clientes.

- Proceder a lavagem das mãos obedecendo aos princípios de assepsia médica, sempre antes de iniciarem e ao terminarem de atender cada cliente.

- Usar gorro, propés, avental e máscara quando executarem a coleta.

- Fazer aplicação de calor, massagem nas mamas, usar oxitocina sintética nas clientes que apresentarem engurgitamento mamário antes de iniciar a extração (manual ou com bomba), para facilitar a ejeção do leite (APPLEBAUM $^{1}$ ).

- Orientar as clientes sobre a prática do aleitamento materno, visando detectar e combater tabus existentes, bem como esclarecer dúvidas.

- Após a coleta, guardar imediatamente o recipiente na geladeira ou freezer, colocando o nome da paciente, a quantidade, a data e a rubrica em rótulo.

- Manter o ambiente limpo e em ordem.

- Manusear o material colhido e utilizado para a extração de leite obedecendo a principios de assepsia cirúrgica.

- Informar a Chefia da Seção sobre qualquer eventual ocorrència no seu estado de saude como: perturbaçōes gastro-intestinais (diarréias e vômitos), infecçōes da oro-faringe, lesões de pele. etc.

- Apresentar-se com rigorosa limpeza pessoal, particularmente cabelos, mãos e unhas curtas.

- Por ocasião da limpeza pelo(a) funcionário(a) da zeladoria, este deverá usar também gorro, avental e propés.

- Realizar a coleta em doadoras portadoras de determinadas doenças infecto-contagiosas no quarto da puérpera, e após a coleta proceder a limpeza e esterilização dos dispositivos da bomba.

- Anotar os medicamentos ou antibióticos utilizados pelas doadoras no formulário de coleta. O leite será inutilizado se for comprovado o efeito nocivo da droga.

- Utilizar gorro, máscara e avental por ocasião da coleta domiciliar.

\section{DO PREPARO E ESTERILIZAÇÃO DO MATERIAL}

Rotina para limpeza das mamadeiras, intermediários e adaptadores de sucção da bomba elétrica.

- Preparar uma soluçāo de $0,5 \%$ do desincrostante em uso com água quente (uma colher das de sopa para 4 litros de água).

- Colocar todo o material nesta solução e deixar por 10 minutos visando o amolecimento dos depósitos do leite ou proteínas.

- Após, proceder a lavagem em água corrente até o desaparecimento total dos resíduos do leite, empregando a escova para limpeza dos frascos e adaptadores dos seios, e um dispositivo para limpeza do interior dos intermediários.

- Em seguida, deixar escorrer sobre a pia. secar e montar o material, de maneira que os intermediários de vidro e de borracha bem como o adaptador fiquem ligados entre si, prontos para uso.

- Após montado, o material deverá ser empacotado em campo de brim e encaminhado para a Central de Material da Maternidade para ser esterilizado em autoclave.

- O pacote deverá ser identificado pela funcionária que o preparou com os seguintes dados: data, assinatura, intermediário e adaptadores de sucção - BLH e CIAM.

É importante ainda colocar aviso: "MATERIAL FRÁGIL".

- Os frascos (mamadeiras) deverão ser empaco- 
tados juntos em outro campo com as tampas soltas no pacote.

- Às 7:00 horas da manhã as bombas deverão ser montadas com material esterilizado.

- Às 12:00 e 18:00 horas deverá ser trocado o material das bombas por outro esterilizado.

Às 21:30 horas deverão ser desmontadas as bombas e preparado o material novamente para ser encaminhado à esterilizaçāo, conforme rotina estabelecida.

- As mamadeiras utilizadas pelo Lactário deverão ser devolvidas para o Banco de Leite já empacotadas e esterilizadas.

- Todo o material em falta ou danificado deverá ser comunicado à Chefia de Seção, com brevidade, para serem tomadas as medidas necessárias em tempo hábil.

- As bombas manuais de material de plástico não poderão ser encaminhadas para esterilização em Autoclave sob pena de se danificarem. As mesmas deverāo ser utilizadas individualmente em pacientes não portadoras de infecção (pele ou mama) e deverão ser muito bem lavadas e enxaguadas com água fervente.

\section{DA ESTOCAGEM}

- Após a coleta em frascos plásticos esterilizados, o leite deverá ser estocado em refrigerador na temperatura de $2^{\mathrm{O}} \mathrm{C} \pm 2^{\mathrm{O}} \mathrm{C}$ se for utilizado dentro de um período de 24 horas. Caso não seja necessário o consumo durante este período, o leite deverá ser estocado no freezer (congelação) na temperatura de $-18^{\circ} \mathrm{C} \pm 2^{\circ} \mathrm{C}$, dentro por um período máximo de 6 meses, devendo ser observada a renovação constante do estoque.

$\mathrm{O}$ descongelamento do leite deverá ser realizado em banho-maria a $37^{\circ} \mathrm{C}$ ou sob água corrente. agitando-se o frasco constantemente.

- O armazenamento do leite coletado não deverá ser feito em recipientes de vidro, já que resulta em redução dos macrófagos, pois estas células se aderem às paredes deste material (PITT \& PORTER ${ }^{17}$ ).

\section{DAS ANALISES LABORATORIAIS}

- As análises do leite são de natureza microbiológica, sendo realizadas três vezes por semana, no Banco de Leite Central.
- Os limites de segurança para contaminantes microbianos no leite humano ordenhado obedecem aos padrōes estabelecidos na literatura (ASSIS $^{2}$, LUCAS \& ROBERTS ${ }^{14}$ ).

- Eventualmente, são realizadas análises de natureza bromatológica e imunológica, determinando-se a proteina total segundo o método micro Kjeldah (ASSIS ${ }^{2}$ ).

- Dentro das análises imunológicas, quantificam-se as imunoglobulinas A. G e M. para a finali dade de pesquisa ( ASSIS $^{2}$ ).

- O leite poderá ser utilizado in natura desde que a contagem de bactérias totais não ultrapasse a $10^{4}$ microorganismos $/ \mathrm{ml}$ e que não haja a presença de colônias de Staphilococcus aureus coagulase positiva ( $\mathrm{ASSIS}^{2}$ ).

- Quando a contagem de microorganismos não se enquadrar nos limites estabelecidos acima, o leite é pasteurizado em aparelho de banho-maria ajustado a $62,5^{\circ} \mathrm{C}$, durante 30 minutos $\left(\mathrm{ASSIS}^{2}\right)$.

\section{DA DISTRIBUIÇĀO}

De acordo com a especialidade e características nutricionais e imunológicas do leite da clientela, o Banco de Leite deverá:

(I) - Em caso de solicitação do leite para recém-nascidos prematuros, segundo: CHANDRA ${ }^{7}$, DAVIES $^{8}$, FOMON $^{10}$, GORDON et alii ${ }^{11}$ e $\operatorname{HEIRD}^{13}$ :

(a) Fornecer ao Lactário o leite fresco da própria mãe.

(b) Quando houver falta do leite da própria māe. fornecer ao Lactário leite preferencialmente fresco e disponível de outras mães de prematuros, desde que a quantidade disponivel atenda às necessidades de seus recém-nascidos e do prematuro que nāo pode ser alimentado com o leite materno.

(c) $\mathrm{Na}$ falta de colostro da própria mãe ou de outras māes de prematuros. fornecer ao Lactário colostro, preferencialmente fresco, das mães de recém-nascidos a termo.

(d) $\mathrm{Na}$ falta do colostro especificado nos itens (a), (b) e (c), fornecer ao Lactário o leite de transiçāo preferencialmente fresco, das mães de recém-nascidos a termo.

(e) $\mathrm{Na}$ falta do colostro especificado nos itens (a), (b) e (c), e do leite de transição, fornecer leite tardio de mães de recém-nascidos a termo.

(II) - Em caso de solicitação do leite para recém-nascidos a termo de baixo peso para idade ges- 
tacional, recém-nascidos a termo com diarréia protraida. outros recém-nascidos de alto risco que necessitem de leite humano ordenhado $\left(\right.$ ASSIS $^{2}$ e RAIHĀ et alii $^{18}$ ):

(a) Fornecer colostro preferencialmente de suas próprias mães.

(b) $\mathrm{Na}$ indisponibilidade, fornecer colostro preferencialmente fresco de outras mães de recém-nascidos a termo.

(c) Na falta de colostro como especificado nos itens (a) e (b) anteriores, fornecer leite de transição preferencialmente fresco, de suas próprias mães ou, na falta deste, leite de outras mães.

(III) - Em caso de solicitação do Posto de Coleta de Hospital Infantil, o Banco de Leite Humano e Central de Informaçōes sobre Aleitamento Materno deverá:

(a) Fornecer o tipo de leite como especificado nos itens (I) e (II), desde que as crianças internadas que necessitem do leite se enquadrem nestas categorias e quando houver disponibilidade do leite de transição e leite tardio fresco ou congelado.

(b) Quando se tratar de crianças portadoras de deficiência imunológica somente poderá ser fornecido o colostro fresco, devido à especificidade do tratamento.

(c) Todos os dias o Lactário do Hospital Infantil deverá informar ao Banco de Leite os recém-nascidos que necessitam de leite humano, especificando sua patologia, para que se possa realizar a classificação do leite que será enviado.

(IV) - Em caso de solicitação, via Receita Médica, de leite para crianças imunologicamente deficientes, o Banco de Leite deverá fornecer colostro fresco disponível de mães de recém-nascidos normais a termo (ASSIS ${ }^{2}$, BARROS $^{4}$ ).

(V) - Todo o leite distribuído pelo Banco de Leite Central ou nos Postos de Coleta deverá ser encaminhado em recipiente de isopor, com recomendação anotada nos frascos (rótulo), contendo: data, assinatura, idade do leite e nome da doadora.

(VI) - As solicitações ao Banco de Leite deverão ser feitas em formulário próprio contendo o tipo e a quantidade de leite requerida, sendo a distribuiçāo feita mediante protocolo (Anexo IV).

(VII) - No Lactário, o fornecimento de leite às crianças de alto risco obedece à seguinte prioridade $\left(\mathrm{ASSIS}^{3}\right)$ :

19) Recém-nascidos prematuros.

29) Recém-nascidos de baixo peso para a idade gestacional.
30) Crianças imunologicamente deficientes.

49) Crianças alérgicas a outros tipos de leite.

50) Recém-nascidos com enterocolite necrotizante.

(VIII) - O controle da entrada e saída do leite deverá ser feito diariamente em formulário próprio (Anexo II) e encaminhado para a Chefia da Seção ao término do mês.

\section{CONCLUSÕES}

As normas e rotinas adotadas pelo Banco de Leite Humano e Central de Informações sobre Aleitamento Materno foram imprescindíveis para o desenvolvimento de suas atividades, por estabelecerem os limites dentro dos quais o setor opera e transmite sua filosofia.

Atualmente, coleta-se uma média de 150 litros de leite por mês, no Banco de Leite Central e em dois Postos de Coleta, podendo-se atender cerca de $60 \%$ dos bebês internados nas Unidades de Tratamento Intensivo da Maternidade e Hospital Infantil.

As normas e rotinas foram estabelecidas a fim de garantir às crianças beneficiadas com o leite oriundo dos Bancos, um produto adequado às suas necessidades.

SANTOS. E. K. A.\& ASSIS, M. A. A. Technical ruber and procedures of the Human Bank Milk and information center on maternal-milk-feeding. Rev. Bras. Enf., Brasília, 38(2): 133-137, abr.jjun. 1985.

\section{REFERÊNCIAS BIBLIOGRÁFICAS}

1. APPLEBAUM, R. M. The obstetrician's approach to the breasts and breast-feeding. J. Reproductive Med., 14:98, 1975 .

2. ASSIS. M. A. A. Estudos sobre a preservaçāo do colostro humano para bancos de leite. Campinas. 1981. Tese (Mestrado) - UNICAMP. Faculdade de Engenharia de Alimentos e Agrícola.

3. _ - et alii. Planejamento de banco de leite humano e central de informaçōes sobre aleitamento materno. Rev. Saúde Prubl., Sāo Paulo, 17(5): 406-12, out. 1983.

4. BARROS, M. D. Imunoglobulinas, Lizozima e Leucócitos. Proteinas e Eletrólitos no Colostro e Leite de Mães de Recém-Nascidos Pré-termo e de Recém-Nascidos a Termo Pequenos Para a Idade Gestacional. São Paulo, 1983. Tese (Doutor) L'SP. Faculdade de Medicina.

5. BEREZIN et alii. Leite Humano - Estudo das imunoglobulinas no colostro de māes de prematuros e de mães de crianças a termo.J. Ped., Rio de Janeiro, 50(4): 123-6, abr. 1981. 
6. BULlEN, J. J. \& ROGERS, H. J. Iron dinbing proteins in milk and resistance to Escherichia coli infections in infants. Brit. Med. J., 69-75, 1972.

7. CHANDRA, R. K. La leche materna y el bebé prematuro. Madres y niños: 6-7, 1982.

8. DAVIES, D. P. Adequacy of expressed breast milk for early growth of preterm infants. Arch. Dis. Childhood, 52:296-301, 1977.

9. FERNÁNDEZ, F. P. et alii. Estudio in la lactancia materna II. Colonización intestinal in recién nacidos alimentados com leche humana. Bol. Med. Hosp. Infantil. 36(4): 605-10, 1979.

10. FOMON, S. J. et alii. Human milk and the smail premature infant. Am. J. Dis. Child., 73: 463-7, op. 1947.

11. GORDON, H. H. et alii. Feeding of premature infants.Am. J. Dis. Child., 73:442-52, 1947.

12. GROSS, S. J. et alii. Elevated IgA concentration in milk produced by mother delivered of preterm infants. J. Pediatrics, 99(3): 389-93, Sep. 1981.

13. HEIRD. W. Feeding the premature infant. Human Milk or an Artificial Formule? Am. J. Dis. Child, 131: 468-9, Apr. 1977.

14. LUCAS, A.\& ROBERTS, C. D. Bacteriological quality control in human banking. Brit. Med. J., 1: 80-2, 1970.

15. MCCLELland. D. B. L. \& McDONALD. T. T. Antibodies to cow's milk protein in human colostrum. The lancet. 2(7997): 1251, 1976.

16. NORDIO. S. et alii. Aspectos nutricionais e metabólicos do aleitamento ao seio. Anais Nestlé. São Paulo, 103: 80-9, set. 1979.

17. PITT, J. \& PORTER. P. B reast milk leukocytes. Pediatrics, 58(5): 769-70, 1976.

18. R $\ddot{A} I H \bar{A}, N$. C. R. et alii. Milk protein quantity and quality in low-birthweight infants: I. Metabolic responses and effects on grow th. Pediatrics, 57(5): 659-74, May 1976. 


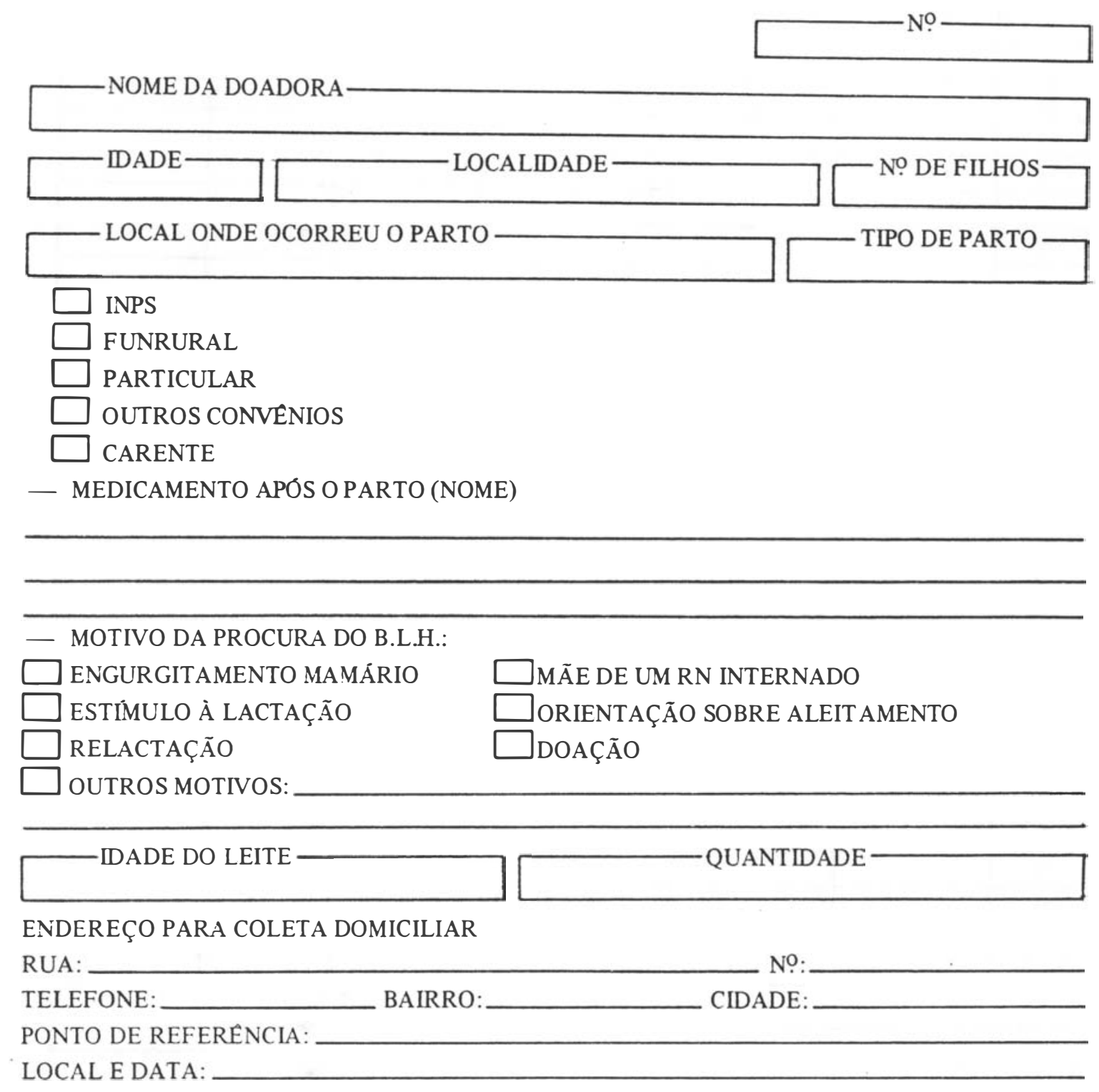




\section{FHSC/MATERNIDADE CARMELA DUTRA}

RELATÓRIO DA DISTRIBUIÇĀO MENSAL - BANCO DE LEITE HUMANO -

\begin{tabular}{|c|c|c|c|c|c|c|}
\hline DIAS & $\begin{array}{l}\text { BERCAARIO } \\
\text { ALTO RISCO }\end{array}$ & \begin{tabular}{|c|} 
HOSP. INFANTIL \\
JOA. GUSMAOO
\end{tabular} & $\begin{array}{c}\text { HOSPITAL } \\
\text { UNIVERSITARIO }\end{array}$ & $\begin{array}{l}\text { HOSPITAL } \\
\text { FLORIANOPOLIS } \\
\end{array}$ & "MAES" & TOTAL \\
\hline \multicolumn{7}{|l|}{01} \\
\hline \multicolumn{7}{|l|}{02} \\
\hline \multicolumn{7}{|l|}{03} \\
\hline \multicolumn{7}{|l|}{04} \\
\hline \multicolumn{7}{|l|}{05} \\
\hline \multicolumn{7}{|l|}{06} \\
\hline \multicolumn{7}{|l|}{07} \\
\hline \multicolumn{7}{|l|}{08} \\
\hline \multicolumn{7}{|l|}{09} \\
\hline \multicolumn{7}{|l|}{10} \\
\hline \multicolumn{7}{|l|}{11} \\
\hline \multicolumn{7}{|l|}{12} \\
\hline \multicolumn{7}{|l|}{13} \\
\hline \multicolumn{7}{|l|}{14} \\
\hline \multicolumn{7}{|l|}{15} \\
\hline \multicolumn{7}{|l|}{16} \\
\hline \multicolumn{7}{|l|}{17} \\
\hline \multicolumn{7}{|l|}{18} \\
\hline \multicolumn{7}{|l|}{19} \\
\hline \multicolumn{7}{|l|}{20} \\
\hline \multicolumn{7}{|l|}{21} \\
\hline \multicolumn{7}{|l|}{22} \\
\hline \multicolumn{7}{|l|}{23} \\
\hline \multicolumn{7}{|l|}{24} \\
\hline \multicolumn{7}{|l|}{25} \\
\hline \multicolumn{7}{|l|}{26} \\
\hline \multicolumn{7}{|l|}{27} \\
\hline \multicolumn{7}{|l|}{28} \\
\hline \multicolumn{7}{|l|}{29} \\
\hline 30 & & & & & & \\
\hline 31 & & & & & & \\
\hline TOTAL & & & & & & \\
\hline
\end{tabular}




\section{BANCO DE LEITE HUMANO E CENTRAL DE INFORMAÇŌES SOBRE ALEITAMENTO MATERNO}

\section{INSTRUÇOEES PARA TIRAR O LEITE EM CASA OU NO TRABALHO *}

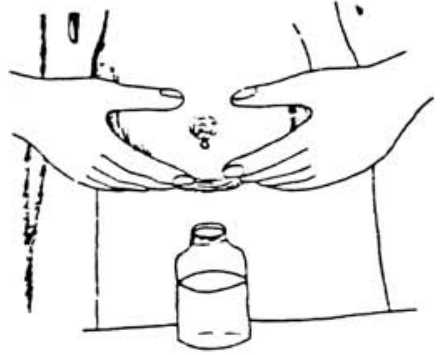

2 - Se preferir usar o tira-leite, utilize água e sabão para lavá-lo juntamente com a mamadeira. Use a escovinha para limpar bem os cantos, enxaguando até a retirada total da espuma.
1 - Você pode retirar o seu leite de peito com as mãos ou com tira-leite. Se usar as mãos lave-as bem com sabão antes de começar a expressão, passando somente água nos seios.

A seguir siga as demais instruções deste Manual.

3 - Colocar a mamadeira dentro de uma panela com água e deixar ferver por 5 minutos.

4 - Em outra panela, colocar as tampas e o tira-leite desmontado e passar água fervente. Salve uma criança doando amor com seu leite.

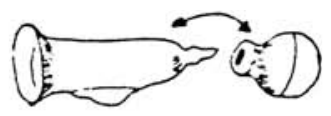

* Para desmontar o tira-leite basta puxar a borracha, soltando-a do vidro.

5 - Escorrer bem a água da mamadeira, da tampa e do tira-leite sem secar dentro.

6 - Apertar a borracha do tira-leite para tirar a água.

7 - Montar a mamadeira e o tira-leite, deixando-os em lugar bem limpo.

De preferência, colocar o tira-leite em uma panela coberta.

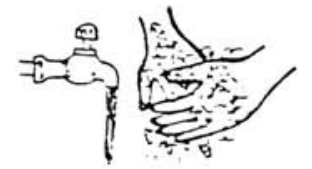

8 - Preparar-se para tirar o leite, lavando as mãos com sabonete e os seios com água.

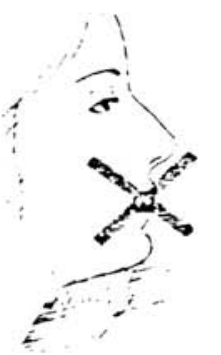

9 - Fique de boca fechada durante a extração do leite, assim ele não se contaminará.

* Além das autoras do trabalho participou na elaboraçāo deste bole tim a Enfa. Rosana Lago Mafessoni 
10 - Apertar a borracha com a mão e colocar o tira-leite no seio, tomando cuidado em deixar a parte alarga. da do vidro para baixo.

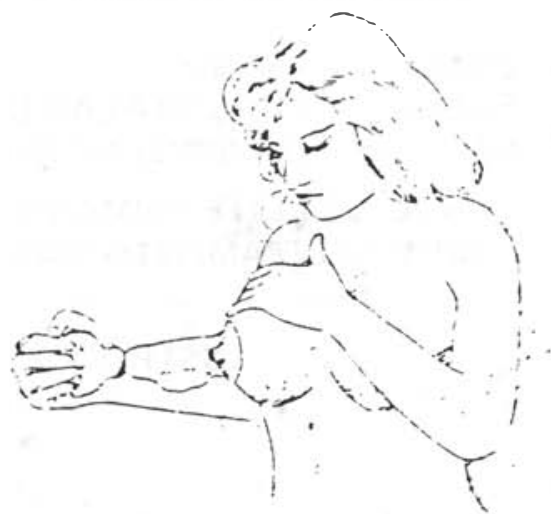

11 - Com a outra mão fazer a massagem no mesmo seio e no sentido da saida do leite.

12 - Ao mesmo tempo ir abrindo a mão que está sobre a borracha.

13 - Assim o leite começará a sair.

14 - Quando acabar a pressão sobre a borracha do tira-leite, colocar a quantidade que saiu de leite na mamadeira. Evitar na medida do possivel que o leite entre na borracha para que o mesmo nāo fíque depositado em seu interior.
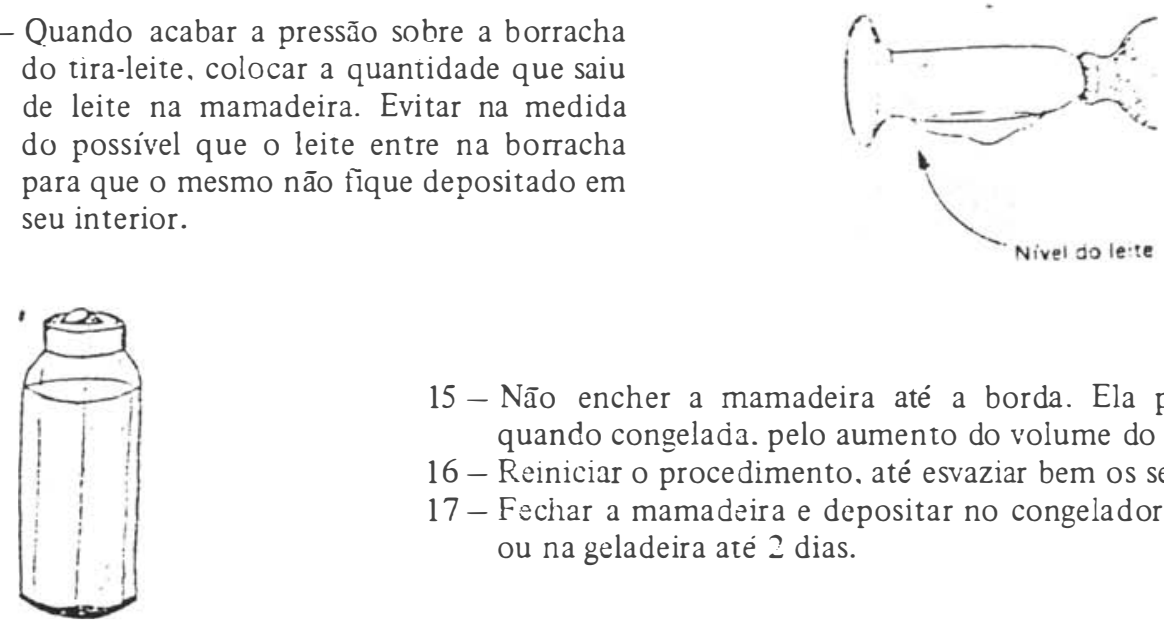

15 - Não encher a mamadeira até a borda. Ela pode estourar quando congelada. pelo aumento do volume do leite.

16 - Reiniciar o procedimento, até esvaziar bem os seios.

17 - Fechar a mamadeira e depositar no congelador até 1 semana ou na geladeira até 2 dias.

18 - Estocar o leite de preferência em mamadeira plástica.

19 - Se o seu seio estiver muito cheio e duro, fazer compressas com água quente e massagea-lo no sentido da saída do leite com óleos que não contenham álcool (vaselina. manteiga de cacau, nujol, azeite).

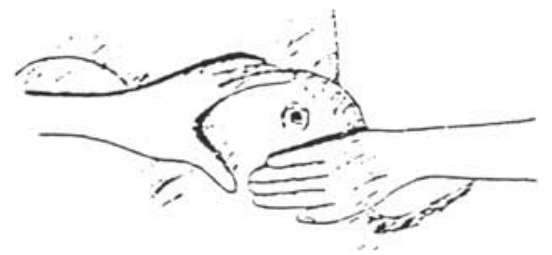

A mãe pode continuar amamentando seu filho com o leite do peito mesmo quando estiver traba- . lhando fora de sua casa

No trabalho arranje um tempo para retirar o leite com a mão ou com a bomba manual. colocando-o numa mamadeira que deverá ser armazenada em geiadeira ou em recipiente de isopor. Assim a mão aumenta a produção de leite e permite que seu tïho seja alimentado da melhor maneira durante a sua ausência. 
A pessoa que cuida do bebê deve aquecer o leite materno em banho-maria, sem nunca deixar ferver. assim o leite ficara morno como o que sai direto do seio. Deve-se usar colher, conta-gotas ou seringa para oferecer o leite ao bebê, pois o uso do bico da mamadeira faz com que o bebê não pegue mais no seio da mãe.

É importante lembrar:

- Que o leite materno é o melhor por ser o mais nutritivo e o mais digestivo para o bebê.

- Que a criança amamentada cria defesas contra doenças e infecções.

Por isso o Banco de Leite Humano e Central de Informações Sobre Aleitamento Materno está à disposiçāo nesta Maternidade, para prestar informações e atendimento em casos de dificuldades.
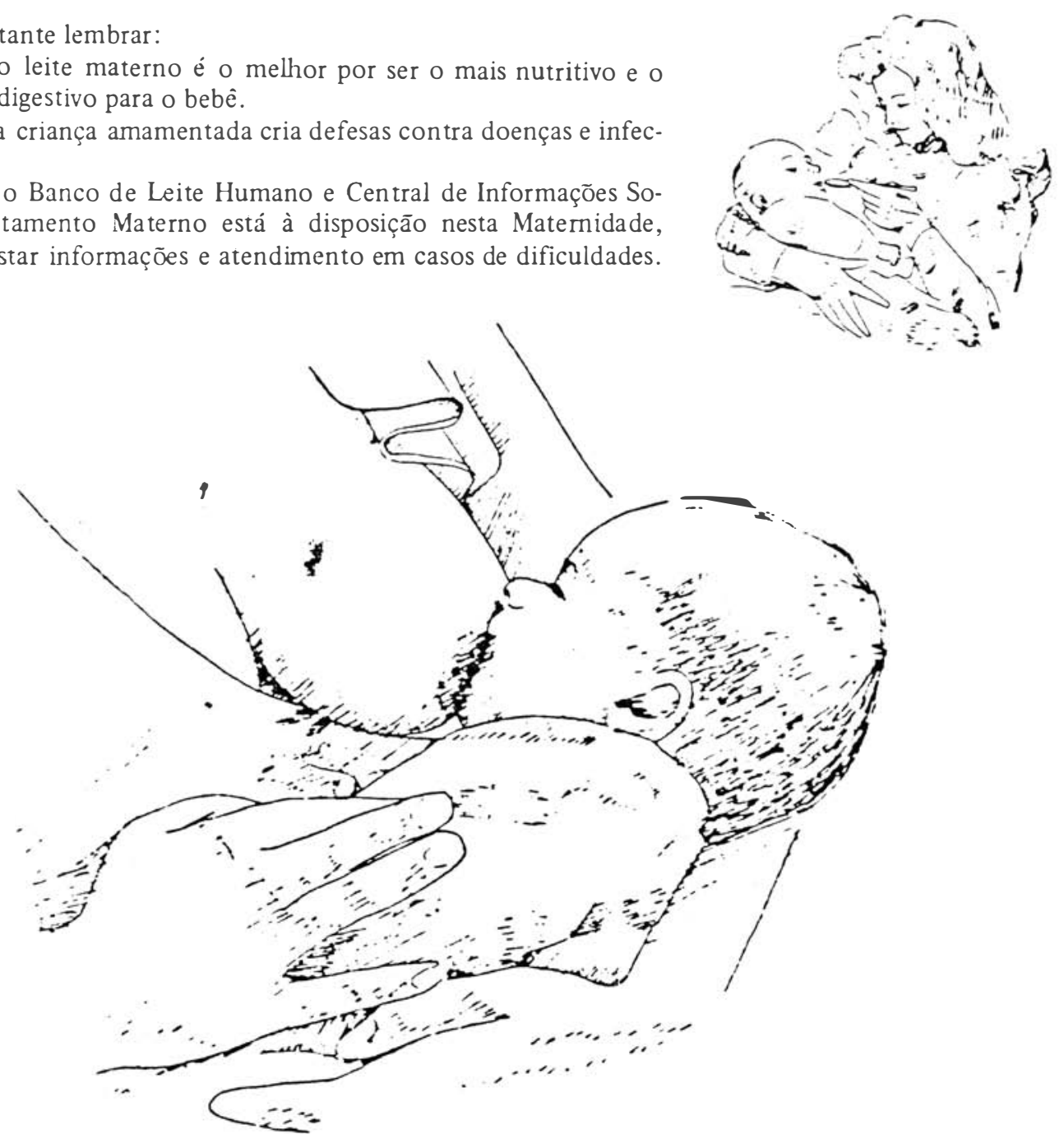

Para doar leite. dirija-se ao Banco de Leite Central situado nesta Maternidade ou basta telefonar que iremos até sua casa.

O leite que você doa é doado somente aos berçários e faz com que os bebês prematuros e gravemente doentes consigam sobreviver e se desenvolver.

Em nome deles nós agradeceinos.

Informaçōes: 22-0699 - Ramal 252

Horário: $\quad 7: 30$ às 21:00 horas (dias úteis)

7:30 às 18:00 horas (sábado - domingo e feriados) 
MATERNIDADE CARMELA DUTRA E C.I.A.M.

BANCO DE LEITE HUMANO E C.I.A.M.

ANEXO IV

NOME DO RECEPTOR

SEXO

IDADE

FILIAÇÃO

DIAGNÓSTICO MÉDICO:

\begin{tabular}{|l|l|l|}
\hline DATA/HORA & $\begin{array}{c}\text { QUANTIDADE PRESCRITA } \\
\text { IDADE DO LEITE }\end{array}$ & $\begin{array}{c}\text { QUANTIDADE OFERECIDA } \\
\text { DADE DO LEITE }\end{array}$ \\
\hline & & \\
\hline & & \\
\hline & & \\
\hline & & \\
\hline & & \\
\hline
\end{tabular}

